\title{
Violência e dor em Conversación al sur, de Marta Traba
}

\author{
Violence and pain in Conversación al sur, de Marta Traba
}

Maria Suely de Oliveira Lopes ${ }^{1}$

\begin{abstract}
RESUMO
Este trabalho debruça-se em torno da obra Conersación al sur (1981) da escritora Argentina Marta Traba. A narrativa aborda relatos da ditadura militar na Argentina vivenciados pelas personagens Irene e Dolores. Os resultados apontam para casos de violência como exemplos comumente encontrados na Argentina em decorrência da Ditadura.
\end{abstract}

PALAVRAS-CHAVE: Literatura. Violência. Dor. Ditadura militar.

\begin{abstract}
This work focuses on the work Conersacion al sur (1981) by the Argentine writer Marta Traba. The narrative addresses reports of the military dictatorship in Argentina experienced by the characters Irene and Dolores. The results point to cases of violence as examples commonly found in Argentina as a result of the Dictatorship.
\end{abstract}

KEYWORDS: Literature. Violence. Pain. Military dictatorship.

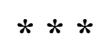

\section{Introdução}

Nossa intenção neste artigo é trazer a questão da violência como interdição dos sujeitos na narrativa Conversación al sur (1981), obra literária latino-americana da escritora argentina Marta Traba, intelectual e representativa para seu país e que produziu diversas obras no campo da

\footnotetext{
1 Doutora em Teoria da Literatura pela Universidade Federal de Pernambuco (UFPE), Professora Adjunta da Universidade Estadual do Piauí (UESPI) atuando nas áreas de Teoria Literária, Crítica Literária, Literatura Brasileira. Atualmente é professora do Mestrado Profissional em Letras(PROFLETRAS) e do Mestrado Acadêmico em Letras( UESPI). É membro do Grupo de Estudos Interdisciplinares em Literatura (INTERLIT) e filiada a ADHILAC. Possui Pós - Doutorado pela Universidade Federal do Piaui-UFPI ,tendo atuado como Investigadora Visitante sob a supervisão de Dra. Marcela Croce na Universidade de Buenos Aires(UBA) Email: suelopes152@hotmail.com, mariasuely@cchl.uespi.br
} 
literatura testemunhal. Sua escrita está inserida no campo dos escritores que, guiados pelo engajamento político, utilizam-se do texto literário para denunciar o terrorismo e a repressão ocorrida durante a ditadura militar.

Sobre a autota

A obra Conversación al sur (1981) traz como tema o golpe militar em 1976 na Argentina resultando na queda do poderio do presidente Juan Domingos Perón que foi marcado por um período turbulento pela ditadura, e que através de perseguições e assassinatos, buscava combater o peronismo e as correntes socialistas e comunistas da época. Os setores populares reivindicavam por seus direitos trabalhistas e sociais e, segundo Grandis (1992), o peronismo sempre esteve ligado às demandas sociais dos âmbitos populares. E para os setores militares este movimento era visto como um fenômeno irracional. Esse período é ressemantizado em Conversación al sur, em que as personagens principais, Irene e Dolores, vítimas de opressão e violência, retomam através da memória alguns fatos da história e, por meio destes, mostram um panorama do regime ditatorial e as marcas físicas e psicológicas que estão guardadas em suas memórias.

Duas mulheres : uma história

A partir de sua experiência como exilada e de tudo que presenciou, Traba narra em Conversación al Sur atos abusivos da ditadura nas décadas de 1970 e 1980 na América Latina, especialmente em países que pertencem ao cone sul (Buenos Aires, Montevidéu e Santiago). Essa obra, como outras que narram as agruras da ditadura, descreve calamidades históricas deixando marcado o comprometimento com o "real", com a memória das vítimas da ditadura e com a sociedade.

O enredo transcorre através de uma conversa entre duas personagens, Irene, ex-atriz de 40 anos, e Dolores, uma militante e escritora de 28 anos. Durante a conversa algumas cenas da ditadura são retomadas e vivenciadas pelas personagens, com o auxilio da memória. Entre uma frase dita e outra 
a ser construída, percebemos os momentos de dor e desespero sentidos pelas vítimas da ditadura. O diálogo proferido pelas duas personagens não deixa de aludir ao sentimento de impotência diante das atrocidades provocadas por esse evento político. Durante a narrativa, Irene e Dolores nos fazem perceber o quanto suas vidas e desejos foram interrompidos, interditados e estilhaçados.

A interdição, no contexto da ditadura, é o ato que se retira de determinada pessoa a possibilidade administrar sua própria vida, impedindo que as pessoas estabeleçam um diálogo com a liberdade de expressão, ao contrário, incentiva a censura e a repressão. A interdição da vida e da liberdade são uma constante nesse tipo de narrativa; os seres são violentados e só alguns, uma pequena minoria, conseguem sobreviver, mas carregam consigo o trauma de uma vida interrompida. Nessa conjuntura, a morte, seja ela física ou não, consiste ser um ato de violência e de interdição das vontades . Em relação a essa questão, lembramos-nos do que afirma Bataille quando descreve a morte de um animal:

Para a maioria, os deuses mais antigos eram animais $\mathrm{e}$ desconhecedores de interditos que limitam originalmente a soberania de um homem. Em primeiro lugar, matar um animal inspirou talvez um forte sentimento de sacrilégio. A vítima, posta coletivamente à morte, assumiu o sentido da divindade. O sacrifício consagrava-a, divinizava-a (BATAILLE,1987,p.54).

De outro modo, sendo animal, a vítima era por antecipação sagrada. O caráter sagrado manifesta a maldição ligada à violência, e o animal jamais se desvia da violência que o anima sem uma segunda intenção.

Em outro contexto, embora diferente mas correlacionado à ditadura, o homem que foi criado segundo a imagem e semelhança de Deus foi sacrificado e retirado dele o direito de sonhar, o direito à vida. Durante a ditadura, em 
nenhum momento é elevado à condição de ser superior. Sua condição humana é relegada ao segundo plano, o da submissão e esquecimento.

Sanjurjo e Feltran (1981, p.55) afirmam que foi pela violência que empreendeu contra a população civil que a última ditadura militar argentina (1976-1983), auto proclamada Proceso de Reorganización Nacional, se tornaria conhecida. Ainda dizem que dentre os métodos utilizados para a imposição do terror, destaca-se a política de desaparecimento forçado daqueles definidos pelas autoridades como "terroristas subversivos" e "inimigos da nação", inimigos de uma nação "ocidental e cristã", como as autoridades militares ressaltariam em seus discursos. E em consequência fica mais evidente a prática do desaparecimento forçado como principal metodologia repressiva desse sistema ditatorial. Podemos citar o número de vítimas, estimado entre 10 mil e 30 mil pessoas 20 , e. a maior parte delas jamais foi localizada, nem se sabe ao certo quando, onde e em que condições foram assassinadas (SANSURJO, FELTRAN, 2015, p.2). Observa-se, como efeito, um processo permamente de luto pelos desaparecidos e de reelaboração de sua memória na esfera pública, sobretudo pelos familiares diretos das vítimas.

Em Conversación al sur (1981), Traba traz o contexto da dor e narra a dolorosa e aterradora espera dos desaparecidos as vésperas de sua execução. Em meio a esse horror, nos limites da ficção e a realidade, a literatura surge como forma de resistência, causando estranhamento e perplexidade. É nessa linha de pensamento que Cândido (1995) compreende a literatura como formadora do pensamento crítico dos indivíduos, tornando-os capazes de reconhecer diferentes pontos de vista. Segundo ele, a literatura - confirma e nega, propõe e denuncia, apoia e combate, fornecendo a possibilidade de vivermos dialeticamente os problemas\| (CANDIDO, 1995, p. 243). Desta maneira, a literatura continua sendo o meio mais eficaz contra a repressão,contra "a morte social, o esquecimentoll (UMBACH, 2012, p. 217)". Ela funciona como um registro da história, que, conforme Assmann (2011) busca reconstruir o que historicamente aconteceu. 
E, assim, a literatura que emerge do horror parece estar além das palavras, na tensão entre a perspectiva política e a subjetiva, ambas elaboradas no nível da linguagem:

O encontro entre as duas mulheres, Irene e Dolores, é uma história que reúne outras histórias que não passam de rupturas ou variações de uma: a da mulher frente à ditadura. A história de Luisa, Elena, Victoria, nora de Irene. O texto de Traba inverte o mito do eterno feminino, trabalhando a relação entre mulheres e história como uma relação agonizante mas ativa onde a existência se transforma em pesadelo, onde predomina o temporal, o relativo sobre o espacial, o absoluto: «vamos nós em partes, irmã, para ver se somos inventores ou testemunhas"(CS, 1981,p. 19).

Isto posto, podemos atestar que do encontro das duas mulheres, Dolores e Irene, ressurgem histórias, entre essas, a questão da violência contra a maternidade. Os filhos foram retirados de suas mães de forma brutal e a dor e a separação transformaram-nas em seres esfacelados. O corpo feminino apartado do seu objeto de desejo torna-se, ao resistir, um objeto de repúdio e seu caráter portador de vida torna-se ambíguo. Logo, na fronteira entre o humano e o animal, as mulheres se tornam entranhas, resgatando o humano do biológico. É por meio da palavra ("essa presença feita de ausência", segundo Jacques Lacan (1995)) que se dá o encontro com a História. A palavra é resgatada pela letra que a simula, a fábula.

De acordo com Perilli (2002), a repressão transforma o sujeito em um objeto, em um corpo violentado, em um corpo torturado, um corpo espancado, um corpo subtraído, um corpo desarmado e diminuído, sendo expurgado dele tudo o que é vida. O corpo "quebrado" de Dolores, os pacientes sangrentos que a cercam, sua incontinência, seus olhos como cavidades, funcionam como uma palavra que escreve uma História: "Se você imagina tudo, o pior, o implausível, o aberrante, você está treinando para a realidade. Acho que as 
coisas são suportáveis apenas se você conseguir imaginar algo pior "(TRABA, 1981 p. 34 .

As mães, principalmente, com o desaparecimento dos seus filhos foram forçadas a demarcarem seus lugares. Do espaço privado (a casa), elas conquistaram o espaço público por excelência (a praça), tornando-se o outro absoluto contra o país que escolhe ignorá-los. O feminino é o lugar da resistência, o materno o da História, em oposição à asfixia da repressão: os gritos de amor contra o silêncio do ódio.

Na narrativa, as palavras foram cortadas por soluços e uivos, como:

Pensei ouvir de vez em quando, onde estão eles, onde estão? mas talvez eu tenha imaginado. No entanto, eles tiveram que perguntar algo que mobilizou a raiva geral, porque a massa de mulheres avançou como uma maré ... Eu fiz o mesmo que as loucas, e não posso dizer o que senti; como se estivessem prestes a arrancar minhas entranhas e agarrá-las com uma força insana para salvá-las (TRABA,1981, p. 89).

A figura materna é uma referência essencial para a trama, um elo indissolúvel e resistente às intempéries: mães angustiadas por não saberem o paradeiro de seus filhos; mães cruéis transformadas em tiranas; mulheres forçadas a abortar com golpes; mulheres torturadas com sequelas que os tornam impossibilitadas para a maternidade; mulheres que abortaram para continuar na luta; mães de luto marchando na Plaza Del Mayo; e fortes laços artificiais, de mãe e filha, surgiram repentinamente entre estranhos . No romance, a expansão do espaço permissível aos indivíduos sob o regime militar encontra-se presente a todo o momento, como, por exemplo, nas passeatas das "Madres de la Plaza de Mayo", as quais, silenciosamente, em seu protesto vão ganhando espaço:

¿Así que éstas eran las locas de Plaza de Mayo? Increíble tal cantidad de mujeres y tanto silencio; sólo se oían pasos rápidos, saludos furtivos. Ni un carro celular, ni un policía, ni un camión del ejército en el horizonte. La casa rosada parecía un escenario irreal, con las 
ventanas cerradas por espesos cortinajes. Tampoco los granaderos estaban montando guardia en la puerta. Fue cuando advirtió la ausencia de los granaderos que la operación del enemigo se le hizo horripilantemente transparente: se borraba del mapa la Plaza de Mayo durante las dos o tres horas de las habituales manifestaciones de los jueves. No podían ametrallar a las locas ni tampoco meterlas presas a todas (TRABA, 1981, p. 87 ).

No relato, afirma Vidal (2004), Traba desafia através da palavra a "autoridade" do regime. Escrevendo desde sua posição marginal de exilada, condena o regime ditatorial através de uma narrativa testemunhal escrita na forma de uma conversação, na que se projeta toda a violência do sistema militar: desamparo, dor, agonia, angústia, horror, são sentimentos presentes na narrativa. A distância do exílio permite a Marta Traba a possibilidade de escrever e elaborar na escrita a experiência traumática da perseguição, da tortura e do encarceramento. De uma literatura marcada pelo trauma, "emerge uma subjetividade fraturada por uma experiência que a excede. As narrativas do exílio estruturam-se em torno do trauma para construir a partir dele uma trama ficcional que tem o compromisso ético de transgredir a resistência da linguagem para poder escrever o real da história" (VIDAL, 2004, p. 20).

O real da história foi à perversa crueldade tanática com que as ditaduras do Cone Sul exerceram sua violência, na grande maioria contra jovens adolescentes, separados de suas famílias, de seus afetos, de suas raízes, amadurecidos prematuramente pela brutalidade das circunstâncias:

[...] Sin decir nada, sin gritar, las mujeres levantaban las fotos lo más alto posible. ¿Para qué si nadie las veía? Calculé que no pasaría mucho tiempo antes de que esas caritas casi infantiles fueran irreconocibles a fuerza de estrujarlas y sobornarlas. Cerca de mí una vieja levantaba con las dos manos una foto de estudio artístico de barrio. La muchacha de la foto sonreía tiesa, ladeando la cabeza como seguramente le había exigido el fotógrafo [...] (TRABA,1981, 89-90). 
Consoante a Masiello, (1987), toda lei sugere o lugar de sua proibição. Como no romance, a conversa sobre os horrores da ditadura está sujeita à vigilância e ao controle, as mulheres do relato encontram maneiras de usar seus próprios corpos para subverter o linear do discurso, que é interrompido a todo o momento nas sucessivas idas ao banheiro ou nos momentos de preparação das comidas. Esse estratagema biológico de resistência permite subverter a ordem linear do discurso, evitando assim, os códigos dos censores, entrecortando o discurso para deixá-lo incompreensível. Nesta narrativa, o corpo - palimpsesto em que se pode ler os diferentes momentos de submissão e de liberação - e o lar tornam-se refúgios "quase seguros" para burlar o sistema, mostrando dessa forma, como a mulher não se encontra necessariamente subordinada à vontade do repressor. O lar - lugar de poder e de perigo - ao ser usado como espaço secreto da clandestinidade, onde as ideias e as conversas resistem à vigilância, cria um refúgio provisório que protege dos perigos e exigências externas do espaço público:

\begin{abstract}
Al igual que los desvalidos lugares de significación, cuya autoridad fue negada por los lenguajes del poder, el hogar y el cuerpo femenino son utilizados para confeccionar un lenguaje suplementario, abriendo así nuevas posiciones desde lãs cuales emitir una crítica a la dictadura. Traba utiliza esas posiciones para volver a considerar la dicotomía entre las esferas pública y privada, y ofrecer un posible espacio liberado donde puedan emerger discursos alternativos (MASIELLO, 1987, p. 27).
\end{abstract}

Observamos que o som da campainha e os fortes golpes na porta são sinais da chegada do terror, anunciando a transformação do espaço. Aquele lar que parecia abrigo seguro e íntimo demonstrando $r$ proteção, ao final da história, torna-se espaço de violência:

Los brutales golpes contra la puerta de la calle las despertaron a las dos al tiempo. Dolores se levantó de un salto y se puso a gritar sin 
control. Corrió hacia el fondo de la casa con Irene tratando de calmarla, pero estaba completamente fuera de sí, tratando sólo de huir o de esconderse. Al final la mujer pudo alcanzarla y empujarla contra un rincón, y así quedaron agazapadas en la oscuridad, animales aterrorizados, escuchando cómo saltaban la cerradura de la puerta y cómo golpeaban sonoramente las botas sobre las baldosas de la sala [...] en ese silencio absoluto, el otro ruido, nítido, despiadado, fue creciendo y, finalmente, las cercó (TRABA, 1981, p. 170).

Com a invasão do espaço doméstico pelo aparato repressivo se dá a "politização do privado". O Estado viola física, ideológica e discursivamente os espaços privados para poder impor e controlar seu poder monológico. Para a ditadura não existe, como assinala Dejbord (2000, p.22), possibilidade de espaço privado, já que até o corpo físico é politizável.

Sobre espaço privado, ressaltamos que o termo casa, antes usado como espaço de acolhimento, pode representar um espaço de reconhecimento da nossa identidade, em especial para nós mesmos. Ao contrário, em Conversación al sur (1981), tal termo passa a ser entendido como o espaço de desconforto, desproteção, tensão e desindentidade tendo em vista a ditadura que toma posse desses espaços privados provocando uma perseguição a todos os passos do sujeitos.

$\mathrm{Na}$ obra em estudo, ressaltamos outro aspecto em meio às perseguições, trata-se do corpo representando lugar de violência; nele e através dele ficam exibidos os ultrajes da da repressão, as marcas da tortura. Os desaparecimentos, a queima ou o afogamento dos corpos servem para evitar sua identificação e revelar a brutalidade sofrida pelo corpo na tortura; todos eles são elementos de denúncia em que o corpo aparece como principal protagonista da agressão. O cadáver é o sobrevivente da ditadura, por isso é necessário escondê-lo, desaparecê-lo, ocultá-lo, enterrá-lo. E quando aparece, é só para dar um aviso à população: "se não coopera, isso também pode acontecer com você". 
A violência do poder, como afirma Dejbord (2000), é sempre semântica: massacrar os rebeldes não serve para nada senão se mata ao mesmo tempo a crônica do massacre. Podemos dizer que o discurso repressivo que domina, elimina o corpo, também oculta e mata outros discursos. É o que podemos confirmar no trecho seguinte:

Mas, "la escritura de oposición [...], devuelve el cuerpo al centro del discurso de manera que pueda hablar la verdad sobre su propia opresión. Mostrando los abusos notórios a que ha sido sometido, El cuerpo expone pues las estrategias del régimen y obtiene una nueva identidad como combatiente" (Idem, p. 26). Dialética do poder e da palavra, do corpo e a palavra: a palavra do poder oculta, a palavra da ficção revela vela revelando. Os esforços do poder para plantar a "peste do esquecimento", enterrando o corpo e a palavra, não servem para nada, pois no final, a palavra esquecida, qual fóssil perdido, sempre reaparece (DEJBORD,(2000, p.26).

Em Conversación al sur (1981), o corpo feminino, ao mostrar as marcas da repressão do regime militar, é um corpo biopolítico, que expõe também a imagem secreta do vínculo maternal com o filho: o corpo-útero configura um novo espaço para a violência. Dolores, uma das interlocutoras da conversação, participante de um grupo subversivo foi torturada no Uruguai, fazendo-a abortar. Conversando numa tarde com Irene - uma atriz de teatro de 40 anos que teme pelo destino de seu filho em Santiago nos dias da queda de Salvador Allende - Dolores recupera sua voz e seu passado. As lembranças das interlocutoras são facilitadas pela memória, tradutora e intérprete dos acontecimentos. $\mathrm{Na}$ conversação, a realidade encontra-se limitada pelo domínio da lembrança. Infiltrando-se silenciosamente pelos interstícios do texto, a lembrança vai nos mostrado que a tortura não é mais que o horror e a dor afrontada no desamparo impiedoso de um corpo nu na mais pavorosa solidão vivida antes da morte: 
Agora eu vivia tentando, ao mesmo tempo, esquecer e me vingar, o que era impossível, porque para me vingar eu não conseguia esquecer. Eu fiz um esforço para me lembrar com a minha testa no chão, naquela rua cor de giz do novo cemitério, uivando por Enrique. Ou eu tive que me reconstruir de novo e de novo e de novo na cama do hospital, com um corpo quebrado a pontapés, amarrado a um soro pingando tubo, acordando-me lentamente no meio do alvo total, [...] pensando muito lentamente, len-tí-si-ma-mente: ele nasceu? a que horas? Tentando com crescente desespero lembrar o que momento eles me levaram para o hospital, quando ele nasceu? onde está? Onde eu estava antes de me levarem ao hospital? Quem me levou, se não fosse Enrique? Até que eu veja, sempre de uma vez e sempre agudamente, a peça da prisão. Eu desmaio .Quantas vezes eu desmaiei no hospital? Muitos dias depois, a enfermeira me disse que $\mathrm{Eu}$ acordei e entrei em coma novamente; O menino? Ah, a garota! Coitada, quase completamente formada. A enfermeira me agarrou a mão. Eu entendi que toda vez eu tentava reconstruir porque eu estava lá, naquele pedaço branco, e cheguei ao quarto de torturas, defendiam-me perdendo-me novamente na escuridão (TRABA, 1981, p. 133).

A ambientação de desespero era constante em todos locais pois esses evidenciam que "os mecanismos da felicidade foram quebrados para sempre. Cada sujeito que desempenha seu papel, não pode escapar de sua realidade: jovens na luta, viajantes clandestinos, [...], [...] mães e pais desaparecidos e indignados, detidos em delegacias de polícia, vítimas na sala de tortura.

De acordo com Agamben (2004, p. 173), o campo de concentração - onde se realizou a mais absoluta conditio in humana" [grifos do autor] é apenas um espaço de exceção. Pedaço de território que é colocado fora do ordenamento jurídico normal, onde a exceção torna-se a norma, e onde qualquer questionamento sobre a legalidade ou ilegalidade daquilo que nele sucede é 
simplesmente desprovido de sentido. No espaço da exceção, a lei é integralmente suspensa para "se impor uma nova lei: "aqui tudo é possível".

Como afirma Montañez (2013), ao entrar no quarto da exceção, os prisioneiros da ditadura ao serem submetidos à ferocidade do torturador, são despojados de todo estatuto político e jurídico, reduzidos integralmente "a vida nua", a pura vida sem qualquer medição; um ser humilhado, sobrevivendo atônito, entre o horror e o medo.

A escrita de Traba, como afima Assis e Cerqueira ( 2017) ${ }^{2}$, é fonte fidedigna da realidade por conta da presença do imaginário. Seguindo esta linha, os fatos contidos em Conversación al sur e em outras narrativas testemunhais podem ser interpelados, mas, contrapondo a esta visão, devemos considerar que "A imaginação é chamada como arma que deve vir em auxílio do simbólico para enfrentar o buraco negro do real do trauma. O trauma encontra na imaginação um meio para sua narração. A literatura é chamada diante do trauma para prestar-lhe serviço (SELIGMANN SILVA, 2008, p.70).

A imaginação a qual o escritor retoma não descarta a idoneidade e valor do texto literário, pois avistamos que este é o elemento que consente a narração de uma realidade tão desumana, que para a vítima muitas vezes é impossível expor. Traba, através de seu engajamento político, mostra-nos por meio de Conversación al sur (1981) o terrorismo da ditadura, a tortura e o sofrimento pelos desaparecidos:

Em Conversación al sur, Marta Traba desafia por meio da palavra a "autoridade" do regime. Escrevendo a partir de sua posição marginal de exilada, condena o regime ditatorial por uma narrativa testemunhal escrita na forma de conversação, na qual se projeta toda a violência do sistema militar: desamparo, dor, agonia, angústia, horror são

\footnotetext{
${ }^{2}$ Travessias Interativas / São Cristóvão (SE), N. 14 (Vol. 7), p. 435-450, jul-dez/2017
} 
sentimentos presentes todo momento no texto (MONTAÑEZ, 2013, p. 155).

As personagens tomadas na obra em estudo legitimam a escrita de Traba pois, testemunham a morte e desaparecimento dos companheiros. Dolores passou pelo terror de ser perseguida e torturada. Escrevia por prazer e vaidade, depois sua escrita passou a ser um meio de defesa. "Es curioso, pero la poesía me defiende de la vida y me defiende de la muerte. ¿Podés entender eso? Porque las dos cosas son una amenaza para mí” (TRABA, 1981, p. 56)5. Irene assegura que entende as razões políticas, o espirito conservador e o fascismo da classe média, mas é impossível compreender a aceitação de que... "Iba a decir "le meta un palo por la vagina a una muchachita hasta que le rompa todos los órganos", porque esa historia real la torturaba, pero se calló y se agarró la cabeza" (TRABA, 1981, p. 167).

A maneira como Marta Traba escreve essa obra e como as personagens expõem suas dores, seus sentimentos e pensamentos, leva-nos a ressaltar a história na perspectiva das vítimas de violência, perseguição e repressão. A ditadura provocou traumas históricos e fraturas na memória, por isso Viñar (1993) considera que silenciar não é prática saudável, pois verbalizar os conflitos e ressentimentos é uma forma de retomarmos a memória e seguir para um esquecimento construtivo. Assim, a memória deve atuar de forma que liberte os indivíduos de fatos traumáticos e que são motivos de perturbação.

\section{Considerações finais}

Em Conversación al sur, Dolores e Irene entre uma lembrança e outra atualizam a conversa . Lembrar e reviver são experiências simultâneas; que possibilitam presumir realidades, curar feridas, trazer à tona sofrimentos, combater medos e até evocar fantasmas.

A ditadura militar agia violentamente contra qualquer pessoa que viesse a se manifestar contra o sistema. Os seus métodos eram agressivos, o que 
levavam os militares a tomarem uma posição totalmente contra a Declaração Universal dos Direitos Humanos, a qual o Brasil já era signatário nesta época.

Traba lida com tempo e espaço narrativos como tempo e espaço no mundo. As últimas passagens enunciam o advento da catástrofe suspensa pela palavra. Embora o discurso das protagonistas dissolva o discurso da repressão, seus corpos sucumbem sob seu efeito.

Se o ruído externo aprisiona as palavras, imobiliza as palavras, a violência fecha vidas. A única coisa duradoura é escrever como descanso. As instruções da autora para percorrer o texto são o título em que os dois substantivos desenham as linhas do itinerário do leitor. Encontramos uma conversa, um diálogo extenso e estranho entre as mulheres. Palavra, linguagem, mulher são associados significativos na convenção social que naturalizou a imagem feminina. E assim nos lembramos das mães da Praça de Maio impedidas de terem seus filhos; avós na Praça de Maio, os familiares desaparecidos, e à humilhação, também se estenderam a amigos e familiares, que até hoje não sabem o paradeiro dos mortos em tortura e guerrilhas. Podemos ressaltar que entre os atos abusivos praticados pelo governo, há um que estilhaça o ser humano: o de terem seu sonhos, seus desejos interrompidos, muitas vezes, sem perspectiva de recomeçarem.

Referências

ASSIS, Luana Isabel de . CERQUEIRA,Gisele Bonfim. Memória e Testemunho no romance Conversación al sur. In: Travessias Interativas / São Cristóvão (SE), N. 14 (Vol. 7), p. 435-450, jul-dez/2017.

ASSMANN, A. Espaços da recordação: formas e transformações da memória cultural. Campinas: UNICAMP, 2011.

AGAMBEN, Giorgio. Homo Sacer (O poder soberano e a vida nua I) (Trad. Henrique Burigo). 1a. reimpressão. Belo Horizonte, Editora UFMG, 2004.

BATAILLE, Georges. O erotismo/tradução de Antonio Carlos Viana. — Porto Alegre : L\&PM, 1987. 
CANDIDO. Antonio O direito à literatura. In: Vários escritos. 3. ed. São Paulo: Duas Cidades, 1995.

DEJBORD, Parizad Tamara. Cristina Peri Rossi: escritora del exílio. Buenos Aires, Galerna, 1998.

LACAN, J. O Seminário livro 4, A relação de objeto. Rio de Janeiro: Jorge Zahar,1995.

MASIELLO, Francine. la argentina durante el Proceso: las múltiples resistencias de la cultura". In: BALDERSTON, Daniel et all.Fiction y politica.La narrativa argenina durante El processo militar.Buenos Aires:Alianza Editorial/Intitute for the study of ideologies \&literature, University of Minnesota,1987.

MONTAÑEZ, Amanda Perez. Jogos de sedução. In: MONTAÑEZ, Amanda Pérez. Vozes do exílio e suas manifestações nas narrativas de Julio Cortázar e Marta Traba. Londrina: Eduel,. p. 109 -176, 2013.

PERILLI, Carmen. Las ratas em la torre de Babel. Bueno Aires: Letra Buena, 1994. PERILLI, Carmen. De sussuros e gritos. Conversación al Sur.In: En El Mundo de lãs Ideas e Ideales. Revista Latino-Americana de Ensayo Fundada em Santiago de Chile.1997.Ano XXII.

SELIGMANN-SILVA, Márcio. A questão dos testemunhos de catástrofes históricas. Psicologia Clínica. Rio de Janeiro, v. 20, n.1, p.65-82, 2008.

SANJURJO,Liliana, FELTRAN, Gabriel. Sobre lutos e lutas: violência de estado, humanidade e morte em dois contextos etnográficos. In:Ciência e Cultura . vol.67 no.2 São Paulo Apr./June 2015.

TRABA, Marta. Conversación al Sur. México: Siglo XXI editores, 1981.

UMBACH, Rosani Ketzer. Violência, memórias da repressão e escrita. In: SILVA, Seligmann et. al. (org.). Escritas da violência: o testemunho. v.1. Rio de Janeiro : 7Letras, 2012. p. 217-227.

VIÑAR, Maren; VIÑAR, Marcelo. Fracturas de memoria: crónicas para una memoria por venir. Montevideo, Uruguay: Ediciones Trilce, 1993. 139 p.

VIDAL, Paloma. A história em seus restos: Literatura e exílio no cone sul. São Paulo, AnnaBlume . Editora, 2004 (Selo Universidade, 279).

Recebido em janeiro de 2021. Aprovado em março de 2021. 